ARTICLE OPEN

\title{
Perception and control of allergic rhinitis in primary care
}

\author{
Pascal Demoly $\mathbb{D}^{1,2 凶}$, Isabelle Bossé ${ }^{3}$ and Pascal Maigret ${ }^{4}$
}

Perception of a chronic illness is a driver of patient behaviour that may impact treatment outcomes. The cross-sectional PETRA study was designed to describe the links between disease perception, patient behaviour and treatment outcomes in adults with allergic rhinitis (AR). Overall, 687 French general practitioners (GPs) included 1929 analysable patients (mean age: 39 years; intermittent/persistent symptoms: $46.2 / 52.3 \%$ ). Of the patients, $14.1 \%$ had also been diagnosed with asthma; $71.7 \%$ had uncontrolled AR (ARCT score $<20$ ), and $53.6 \%$ had a good perception of their illness (BIPQ score $<5$ ). Factors significantly associated with poor perception of AR were ENT (ear/nose/throat) complications, nasal pruritus, uncontrolled AR and asthma. A strong negative correlation was observed between the BIPQ and ARCT scores: the poorer the patient's perception, the less the AR was controlled. Although no causal relationship could be drawn, GP-driven improvement of AR perception could lead to better control of symptoms.

npj Primary Care Respiratory Medicine (2020)30:37; https://doi.org/10.1038/s41533-020-00195-8

\section{INTRODUCTION}

According to the World Health Organization (WHO), chronic diseases are the leading cause of morbidity and mortality worldwide, accounting for $43 \%$ of the global burden of disease (as per the 2002 report; 60\% expected in 2020). Chronic diseases are mainly related to ageing of the population, lifestyle and environmental changes. Poor control of chronic diseases represents a public health burden and, consequently, patients need to be managed with the best evidence-based strategies possible, both at the patient and the community level'.

There is no consensual definition of 'disease control', but it could be described as the achievement of therapeutic objectives, or a reduction of symptom severity to acceptable levels through optimised treatment. Control of a chronic disease therefore requires that treatments be adjusted for individual comorbidities and risk factors, as per guidelines, as well as the patient's personal involvement. Patient care is therefore moving from 'bulk' to stratified medicine, pending future personalised and precision medicine. The personal involvement of each patient is correlated with his/her perception of the disease and the associated treatments used for its control. Disease perception corresponds to cognitive and emotional representations of the illness and health threat, and encompasses several dimensions such as identity, consequences, cause, timeline, cure or control ${ }^{2}$. It is possible to activate a virtuous circle where perception and control can be improved, as shown with asthma ${ }^{3,4}$.

The prevalence of allergic rhinitis (AR) is high (around 400 million people worldwide ${ }^{5}$, nearly a third of the adults in France in $2009^{6}$ ), but it is often poorly self-recognised by patients, and also poorly controlled ${ }^{7}$. In 2001, at the initiative of the $\mathrm{WHO}$, in the framework of the first ARIA (Allergic Rhinitis and its Impact on Asthma) workshop, a group of experts proposed a classification of $\mathrm{AR}$ in order to establish a consensual therapeutic approach based on scientific and clinical evidence. In the 2008 update of the ARIA guidelines, the principle that the upper and lower respiratory tracts are a continuum forming a unified airway was reaffirmed, and $A R$ was reclassified based on clinical symptoms and quality of life scores ${ }^{8}$. Although AR is described by patients as disabling, care is neither optimal nor consistent with recommendations ${ }^{9-11}$ and, as shown in France, patients with severe AR consult a doctor on average 7 years after the onset of the disease ${ }^{12}$. The economic burden of the disease is weighed down by inadequate patient management ${ }^{13}$.

In this context, the PETRA study was designed to assess the management of $A R$ by patients and their general practitioners (GP), and to describe the links between disease perception, patient behaviour and treatment outcomes. The main objective of the study was to precisely identify and describe factors associated with poor perception of the disease in a population of patients with AR.

\section{RESULTS}

Characteristics of patients

Overall, 687 GPs participated in the PETRA study and a total of 2001 patients were included between May and October 2017. Of the patients, 1929 were retained for analysis as they met all the selection criteria and had returned their self-questionnaires. Most patients $(88.7 \%)$ were included between May and July. The characteristics of the patients and their AR are presented in Table 1. Their medical care, including previous treatments and those prescribed on the visit day, are described in Table 2. Many patients (40.3\%) declared they were not satisfied with their AR treatment. Regarding the patients' knowledge of the disease, most of them $(81.1 \%)$ knew that allergy was an immune system disorder; $60.5 \%$ cited asthma as a complication of AR and $73.6 \%$ thought that AR was a risk factor for developing asthma. In addition, $63.9 \%$ indicated that AR is a chronic and incurable disease. Almost all patients were convinced that prescription drugs were more effective than over-the-counter drugs (96.3\%), and that limiting allergen exposure was an effective preventive measure (90.9\%).

The mean Allergic Rhinitis Control Test (ARCT) score was $17.3 \pm$ 3.5 points, with AR considered as uncontrolled in $71.7 \%$ of patients (ARCT score $<20$ ).

${ }^{1}$ Division of Allergy, Department of Pulmonology, Hôpital Arnaud de Villeneuve, University Hospital of Montpellier, Montpellier, France. ${ }^{2}$ Sorbonne Université, UMR-S 1136 INSERM, IPLESP, EPAR Team, Paris, France. ${ }^{3}$ Allergology Office, La Rochelle, France. ${ }^{4}$ Menarini France, Rungis, France. ${ }^{凶}$ email: pascal.demoly@inserm.fr 
Table 1. Characteristics of patients and of allergic rhinitis.

\begin{tabular}{|c|c|c|}
\hline Characteristics & Description & $\begin{array}{l}\text { Analysed } \\
\text { population } \\
N=1929\end{array}$ \\
\hline Sex & Male/Female & $49.8 \% / 50.2 \%$ \\
\hline \multirow[t]{2}{*}{ Age } & & $\begin{array}{l}38.8 \pm \\
14.4 \text { years }\end{array}$ \\
\hline & {$[18-30] /[30-50] />50$ years } & $\begin{array}{l}34.8 \% / 43.0 \% / \\
22.2 \%\end{array}$ \\
\hline Living area & $\begin{array}{l}\text { Big city/urban zone/village/ } \\
\text { rural area }\end{array}$ & $\begin{array}{l}12.1 \% / 40.6 \% / \\
34.0 \% / 13.3 \%\end{array}$ \\
\hline Smoking & No/passive/active & $\begin{array}{l}73.4 \% / 6.8 \% / \\
19.8 \%\end{array}$ \\
\hline Familial history of allergy & Yes & $53.6 \%$ \\
\hline \multirow[t]{2}{*}{ Seniority of AR } & First episode & $17.6 \%$ \\
\hline & $\begin{array}{l}\text { Duration from onset } \\
\text { (if }>1 \text { st episode) }\end{array}$ & $\begin{array}{l}10.2 \pm \\
9.0 \text { years }\end{array}$ \\
\hline \multirow[t]{6}{*}{ ARIA classification } & Mild and intermittent & $28.4 \%$ \\
\hline & $\begin{array}{l}\text { Moderate or severe and } \\
\text { intermittent }\end{array}$ & $18.5 \%$ \\
\hline & Mild and persistent & $14.1 \%$ \\
\hline & $\begin{array}{l}\text { Moderate or severe and } \\
\text { persistent }\end{array}$ & $39.0 \%$ \\
\hline & Mild/moderate or severe & $42.6 \% / 57.4 \%$ \\
\hline & Intermittent/persistent & $46.9 \% / 53.1 \%$ \\
\hline PAREO questionnaire ${ }^{a}$ & Total score & $9.0 \pm 2.7$ \\
\hline Nasal itching & $\begin{array}{l}\text { None or mild/moderate } \\
\text { or severe }\end{array}$ & $39.3 \% / 60.7 \%$ \\
\hline Anosmia & $\begin{array}{l}\text { None or mild/moderate } \\
\text { or severe }\end{array}$ & $68.4 \% / 31.5 \%$ \\
\hline Rhinorrhea & $\begin{array}{l}\text { None or mild/moderate } \\
\text { or severe }\end{array}$ & $18.0 \% / 82.0 \%$ \\
\hline Sneezing & $\begin{array}{l}\text { None or mild/moderate } \\
\text { or severe }\end{array}$ & $17.2 \% / 82.8 \%$ \\
\hline Nasal obstruction & $\begin{array}{l}\text { None or mild/moderate } \\
\text { or severe }\end{array}$ & $27.6 \% / 72.5 \%$ \\
\hline \multirow[t]{2}{*}{ Ocular symptoms } & Yes & $64.1 \%$ \\
\hline & Duration from onset (if yes) & $6.6 \pm 8.6$ years \\
\hline \multirow[t]{6}{*}{ Comorbidities } & At least one & $30.4 \%$ \\
\hline & Asthma & $14.1 \%$ \\
\hline & Atopic eczema & $12.3 \%$ \\
\hline & Contact dermatitis & $8.2 \%$ \\
\hline & Nasal polyps & $4.5 \%$ \\
\hline & Allergic keratitis & $1.4 \%$ \\
\hline \multirow{4}{*}{$\begin{array}{l}\text { History of ENT } \\
\text { complications }\end{array}$} & At least one & $20.2 \%$ \\
\hline & Sinusitis & $13.8 \%$ \\
\hline & Recurrent ENT infections & $7.6 \%$ \\
\hline & Otitis media with effusion & $2.6 \%$ \\
\hline \multirow{9}{*}{$\begin{array}{l}\text { Aeroallergen } \\
\text { responsible for AR }\end{array}$} & Known/unknown & $60.3 \% / 39.7 \%$ \\
\hline & If known: & \\
\hline & Grass pollen & $74.4 \%$ \\
\hline & Mites & $44.9 \%$ \\
\hline & Tree pollen & $44.7 \%$ \\
\hline & Herbaceous pollen & $29.5 \%$ \\
\hline & Animal dander & $18.8 \%$ \\
\hline & Fungal spores & $8.9 \%$ \\
\hline & Polysensitisation & $66.9 \%$ \\
\hline
\end{tabular}

\begin{tabular}{|lll|}
\hline Table 1 continued & & \\
\hline Characteristics & Description & $\begin{array}{l}\text { Analysed } \\
\text { population } \\
N=1929\end{array}$ \\
\hline $\begin{array}{lll}\text { Other known allergens } \\
\text { responsible for allergy }\end{array}$ & At least one & $9.8 \%$ \\
& Food & $4.5 \%$ \\
& Chemical & $5.5 \%$ \\
\hline
\end{tabular}

${ }^{a}$ Each symptom scored 0-absent, 1-mild, 2-moderate, or 3-severe, for a total score ranging from 0 to 15 . Values are mean \pm standard deviation for continuous variables, and \% of classes for categorical variables.

\section{Factors associated with poor disease perception}

The mean Brief Illness Perception questionnaire (BIPQ) score was $4.8 \pm 1.0$ points, with perception of $A R$ considered as good in $53.6 \%$ of patients (BIPQ score [0-5]), poor in $44.6 \%$ (BIPQ score [5-7]) and very poor in 1.8\% (BIPQ score [7-10]). Univariate analysis identified several factors significantly associated with poor disease perception: smoking, intense anosmia, ocular symptoms, AR comorbidities (asthma, atopic eczema, nasal polyps, allergic keratitis, contact dermatitis, ear-nose-throat [ENT] complications) and poor control of AR. Subsequent multivariate logistic regression analysis demonstrated the links between the factors significantly associated with poor disease perception, i.e. BIPQ score [5-7] (Fig. 1): the presence of ENT complications (OR: 1.5; $95 \% \mathrm{Cl}:[1.2 ; 1.9]$ ), significant or moderate nasal pruritus (OR: 2.6; $95 \% \mathrm{Cl}$ : $[1.6 ; 4.1]$ and $1.8 ; 95 \% \mathrm{Cl}$ : [1.2; 2.7], respectively), uncontrolled AR (OR: 0.7 for 1 point more on the ARCT score; $95 \% \mathrm{Cl}$ : [0.7; $0.8]$ ) and asthma (OR: $1.5 ; 95 \% \mathrm{Cl}:[1.2 ; 2.0])$. The factors significantly associated with a very poor perception of AR (BIPQ > 7) were asthma (OR: $5.1 ; 95 \% \mathrm{Cl}$ : $[2.5 ; 10.4]$ ), allergic keratitis (OR: 9.6; $95 \% \mathrm{Cl}$ : $[2.5 ; 36.9]$ ) and uncontrolled $\mathrm{AR}$ (OR: 0.5 for 1 point more on the ARCT score; $95 \% \mathrm{Cl}$ : $[0.5 ; 0.6])$.

Patients with mild AR symptoms had a better perception of their disease (according to the BIPQ score) than those with moderate to severe symptoms, as shown in Fig. 2.

Correlations between disease perception and disease control A strong negative correlation was observed between the BIPQ and ARCT scores $(R=-0.57 ; p<0.0001)$ : the poorer the patient's perception, the less the AR was controlled. The correlation was mainly based on a few specific questions of the BIPQ, such as 'How does your disease affect your life?' $(R=-0.59 ; p<0.0001)$, 'How does your disease affect you emotionally?' $(R=-0.50 ; p<0.0001)$ and 'What is the frequency of your symptoms?' $(R=-0.45 ; p<$ 0.0001). Among the well-controlled patients (ARCT $>20$ ), $84.9 \%$ had a good perception of their illness $(B I P Q<5)$ versus $41.1 \%$ of the poorly controlled patients (ARCT $\leq 20 ; p<0.001)$. The mean BIPQ score was also significantly lower in well-controlled patients (indicating a better perception) than in others (4.0 versus 5.1; $p<0.001)$.

Factors associated with poor disease control

Among the patients with poorly controlled AR, $10.1 \%$ thought that reducing exposure to allergens was not an effective preventive measure, whereas that opinion was shared by only $5.9 \%$ of the patients in whom the disease was well controlled. Almost all the patients believed that prescription treatments were more effective than over-the-counter medications. However, $4.2 \%$ of the poorly controlled patients believed that prescription treatments were not more effective compared to $2.5 \%$ of the well-controlled patients. Allergen immunotherapy was perceived equally by all 


\begin{tabular}{|c|c|c|}
\hline Characteristics & & $\begin{array}{l}\text { Analysed } \\
\text { population } \\
N=1929\end{array}$ \\
\hline \multirow[t]{5}{*}{ AR follow-up } & First consultation for AR & $34.3 \%$ \\
\hline & Regular follow-up by GP & $57.4 \%$ \\
\hline & $\begin{array}{l}\text { Regular follow-up by an } \\
\text { allergy specialist }\end{array}$ & $2.0 \%$ \\
\hline & $\begin{array}{l}\text { At least one consultation } \\
\text { with an allergy specialist }\end{array}$ & $36.9 \%$ \\
\hline & Unknown care course & $6.2 \%$ \\
\hline \multirow[t]{4}{*}{ Main consultation reason } & Immediate release & $56.6 \%$ \\
\hline & Treatment renewal & $35.1 \%$ \\
\hline & $\begin{array}{l}\text { Prescription of long-term } \\
\text { treatment }\end{array}$ & $30.7 \%$ \\
\hline & $\begin{array}{l}\text { Change/adjustment of } \\
\text { ongoing treatment }\end{array}$ & $16.4 \%$ \\
\hline \multirow{8}{*}{$\begin{array}{l}\text { Ongoing symptomatic } \\
\text { treatment }\end{array}$} & At least one & $64.6 \%$ \\
\hline & Oral anti-H1 & $59.9 \%$ \\
\hline & Intranasal steroids & $27.6 \%$ \\
\hline & Intranasal anti-H1 & $14.1 \%$ \\
\hline & Intraocular cromone & $11.0 \%$ \\
\hline & Intraocular anti-H1 & $10.2 \%$ \\
\hline & $1 / 2 / 3 />3$ therapies & $\begin{array}{l}19.6 \% / 22.5 \% / \\
17.8 \% / 4.6 \%\end{array}$ \\
\hline & Self-medication & $15.7 \%$ \\
\hline \multirow{7}{*}{$\begin{array}{l}\text { Prescribed symptomatic } \\
\text { treatment }\end{array}$} & At least one & $99.5 \%$ \\
\hline & Oral anti-H1 & $97.7 \%$ \\
\hline & Intranasal steroids & $47.8 \%$ \\
\hline & Intranasal anti-H1 & $24.7 \%$ \\
\hline & Intraocular cromone & $21.7 \%$ \\
\hline & Intraocular anti-H1 & $19.5 \%$ \\
\hline & $1 / 2 / 3 />3$ therapies & $\begin{array}{l}20.1 \% / 34.2 \% / \\
35.0 \% / 10.7 \%\end{array}$ \\
\hline \multirow[t]{10}{*}{ Allergen immunotherapy } & Yes, whenever & $7.4 \%$ \\
\hline & Yes, ongoing & $2.2 \%$ \\
\hline & Against: & \\
\hline & Mites & $5.9 \%$ \\
\hline & Grass pollen & $5.7 \%$ \\
\hline & Tree pollens & $2.7 \%$ \\
\hline & Herbaceous pollen & $1.8 \%$ \\
\hline & Animal dander & $1.6 \%$ \\
\hline & Fungal spores & $0.9 \%$ \\
\hline & Other & $0.4 \%$ \\
\hline \multirow[t]{5}{*}{ Referred to a specialist } & Yes: & $15.1 \%$ \\
\hline & Allergy specialist & $12.2 \%$ \\
\hline & Lung specialist & $2.8 \%$ \\
\hline & ENT specialist & $2.6 \%$ \\
\hline & Dermatologist & $0.7 \%$ \\
\hline \multirow[t]{2}{*}{ Sick leave prescription } & Yes & $1.6 \%$ \\
\hline & Duration (if yes) & $4.8 \pm 2.7$ days \\
\hline
\end{tabular}

patients regardless of the level of AR control with $53.7 \%$ declaring that it could cure AR.

\section{DISCUSSION}

PETRA was a large cohort of adults with AR (1929 patients analysed) observed in real-life conditions in a primary care setting (GP's office) very representative of the management of AR patients in France. Almost $90 \%$ of the patients were recruited into the cross-sectional study between May and July (2017), which is a high-risk period for many aeroallergens. Pollens, which are abundant in this period, were often the causal agents of AR in this cohort. Symptom onset likely prompted the visit to the GP for most patients, particularly for those in whom the causative allergen remained unidentified or for whom the visit was a first for AR (about one third of the cohort in each situation).

The study data confirmed that disease control of patients managed in a primary care setting was poor (71.7\% of patients), which is consistent with the results of another French cohort followed by $\mathrm{GPs}^{14}$. In addition to the ARCT questionnaire assessing disease control, we also applied the BIPQ questionnaire to assess disease perception. The main objectives of the PETRA study were to identify the factors associated with poor perception of $A R$ and how perception relates to control. Interestingly, the ARIA classification (four classes) was not found to be significantly associated with AR perception, although, in addition to annoying symptoms (nasal pruritus) and comorbidities (asthma, keratitis, ENT complications), a low ARCT score was significantly associated with a high BIPQ score: the poorer the patient's perception, the less the AR was controlled. This observation, derived from the multivariate analysis, was confirmed by the significant negative correlation found between the ARCT and BIPQ scores. It is now recognised that disease perception is linked to patient behaviour. Several studies conducted worldwide in various clinical situations all suggest that interventions designed to change disease perception can improve health incomes ${ }^{4,15}$. In this context, initiating a virtuous circle in which disease control is improved together with disease perception and vice versa can only be beneficial, and disease information is key to this. First, a public health campaign, which should also involve pharmacists, could encourage patients to see a GP for any recurrent episodes of runny nose, sneezing and eye-watering. A third of the patients in the PETRA cohort had seen their GPs for the first time for AR symptoms, and only half the patients were followed regularly for the condition despite their symptoms being present for an average of 8 years (a delay consistent with a previous French survey ${ }^{16}$ ) with the treatment appearing inadequate in most cases (low use of intranasal steroids or allergen immunotherapy, for instance). Secondly, once the GP has been approached by the patient, he/she becomes the front-line intermediary regarding the dispensing of information. Most patients recognise AR symptoms fairly well and have a good knowledge of the allergenic agent responsible for their condition as shown in this study; some of them, however, do not link AR to its potential complications and comorbidities. Efforts should be made to inform patients about the causes and consequences of $A R$, its frequent association with asthma, and the need to monitor and care for the entire respiratory system, the aim being to increase disease awareness and AR control. Asthma and keratitis are warning signs that should be used to raise patients' awareness about their disease as they are significantly associated with very poor perception of AR. Therapeutic education is also crucial in disease management. The study showed that about $40 \%$ of patients were dissatisfied with their treatment, although it had been prescribed by a physician in most cases: this result seems to indicate that overall management 


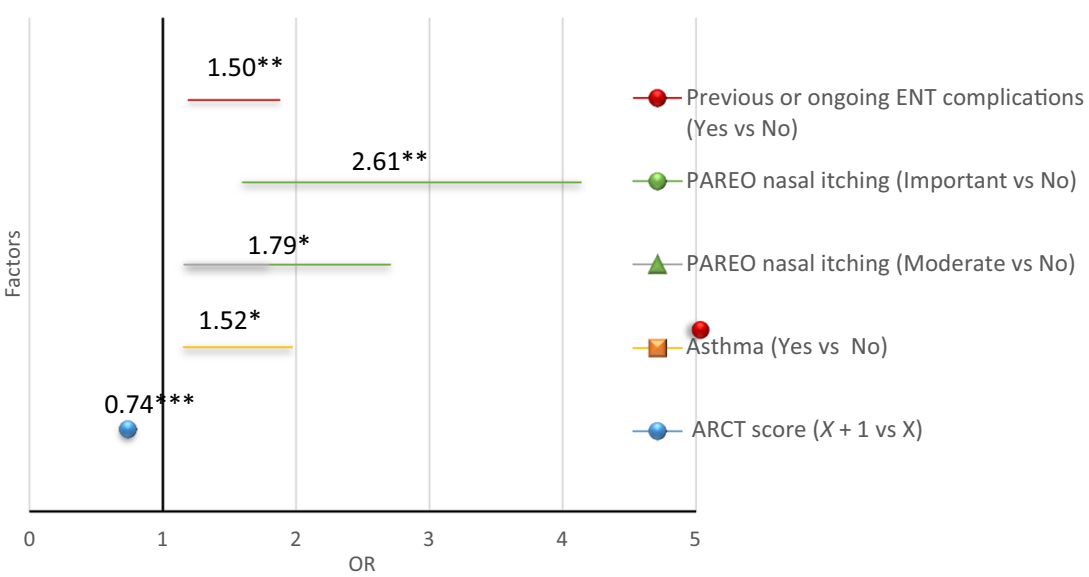

Fig. 1 Factors associated with poor perception of AR. Poor perception of AR was defined by a BIPQ score [5-7]. Odds ratios (OR) were determined using multivariate logistic regression. An OR $>1$ indicates an excess risk of poor perception; the higher the ARCT score, the better the control. The bar represents the $95 \%$ confidence interval $(95 \% \mathrm{Cl})$ of OR ${ }^{*} p<0.05 ;{ }^{* *} p<0.001 ;{ }^{* *} p<0.0001$ (Wald test).

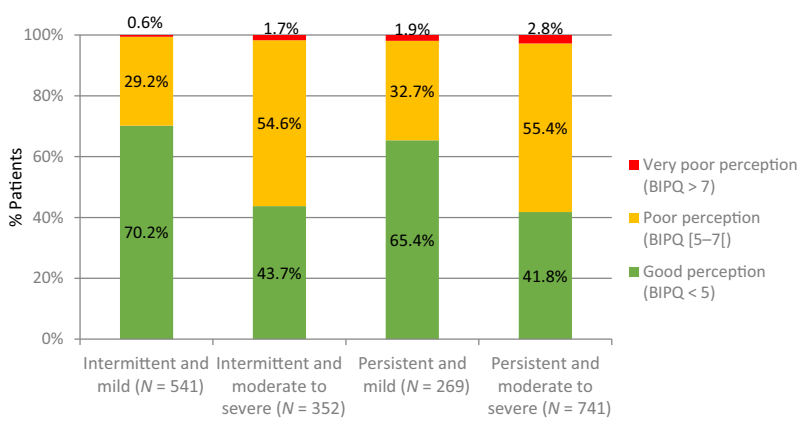

Fig. $2 \%$ patients with various perception (BIPQ) scores in the 4 ARIA severity groups. Perception of AR according to the ARIA classification.

is poorly adapted. In addition, about one third of patients were unable to indicate that $A R$ is a chronic disease. This suggests that most patients are not aware that $A R$ requires long-term management in addition to short-term treatment during periods of exacerbation. As for any chronic disease, GPs should encourage patients to become active participants of their own care. Regular patient follow-up should not be considered as an extraneous expense as the visits can be used to reinforce education and compliance and avoid disease exacerbations, which certainly generate the most costs in any chronic disease, whether psychologically, functionally or socially, and sometimes even alter the prognosis of the disease in the long term. Follow-up visits can also serve to update patients on any new knowledge gained about the disease ${ }^{13}$.

General practitioners also play a crucial role in referring $A R$ patients to allergy specialists when necessary to step up treatment and avoid disease worsening; decision trees can help GPs to determine when referral to a specialist might help ${ }^{17}$. In this study, $15 \%$ of patients were referred to an allergy specialist at the end of the visit. Patients followed by GPs present milder clinical profiles than those followed by specialists. Indeed, $56.6 \%$ of patients in the PETRA cohort had moderate to severe symptoms, and the pattern was persistent in $52.3 \%$ of them, whereas the rates were $80 \%$ and $65.8 \%$, respectively, in the French REALIS study conducted by lung or allergy specialists. In addition, the prevalence of asthma was $14.1 \%$ in the PETRA study versus $40.3 \%$ in the REALIS study ${ }^{18}$. In this cohort, only $2 \%$ of patients regularly saw an allergy specialist. Although the subgroup is very small, these patients tended to have a better knowledge of their disease and were treated more frequently with allergen immunotherapy.
Defending the right of access of patients with respiratory allergies to the best possible care is a public health matter that requires GPs and allergy specialists to combine their efforts. Medicine is at best stratified nowadays and hopefully it will soon become personalised thanks to such optimised patient care. Nonetheless, access to allergists in France is difficult due to their rarity. This may change in the future, however, with allergology having become a full specialty in 2017 and the increase in awareness of public authorities, health professionals and the general public about the consequences of a disease that is still too often trivialised or ignored ${ }^{16}$.

This study presents some limitations. First, the sample of GPs may not be representative of French practitioners (excess of men, non-homogenous regional repartition, participation likely to be related to a specific interest in allergy, etc.). Secondly, the crosssectional study provides a single picture of a cohort of AR patients and only suggests ways to improve overall disease control, which remain to be explored.

In conclusion, the PETRA cohort included a high proportion of patients with moderate to severe AR symptoms and a low level of disease control. It appeared that many patients were not satisfied with their treatment and did not perceive their disease very well. Poor disease perception was associated with the presence of ENT complications, moderate to severe nasal pruritus, asthma and poor disease control. Although no causal relationship could be drawn from this cross-sectional study, results suggest that enhancing perception of AR could be beneficial to patients and lead to better control of symptoms. GPs, as front-line health professionals with regard to patients, are key to improving their cognitive representations of AR.

\section{METHODS}

Design and regulatory context

PETRA was an observational, cross-sectional, prospective, multicentre study conducted in France by GPs. The protocol, patient information sheet and all other documents were submitted to and approved by the Advisory committee on information processing in health research matters (Comité Consultatif sur le Traitement de I'Information en Matière de Recherche dans le Domaine de la Santé) and the National commission on data processing and liberties (Commission Nationale de l'Informatique et des Libertés) before the study started, in compliance with French legislation and ethical regulations. The study was not registered, as it was not mandatory in France for non-interventional studies at the time it was designed. Patients aged 18 years or more, already diagnosed with $A R$, or strongly presumed to be suffering from $A R$, were included during a routine visit after being informed about the study and having expressed their non-opposition to 
personal data collection as per currently applicable French regulations (written consent is not required for non-interventional studies).

\section{Data collection}

General practitioners collected data on paper-based case report forms: socio-demographic characteristics, living conditions, history of AR including the ARIA classification of severity ${ }^{8,19}$ and the PAREO (Prurit/nasal pruritus, Anosmie/anosmia, Rhinorrhée/rhinorrhea, Eternuements/sneezing, Obstruction nasale/nasal obstruction) score for symptom intensity (each of the five symptoms graded from 0 to 3 , for a total ranging from 0 to 15$)^{20}$ diagnosis of $A R$, and ongoing and prescribed treatments. Patients filled in self-questionnaires about their knowledge of $A R$ and associated diseases and treatments, disease control (ARCT questionnaire, the total score of which ranged from 5-poorest control to 25-best control ${ }^{14}$ ), and illness perception (BIPQ, the total scores of which ranged from 0 -best perception to 10 - poorest perception ${ }^{2,15}$ ).

\section{Statistical methods}

The main objective of the study was to identify the factors associated with a poor perception of the disease, defined by a BIPQ score $\geq 5$. Univariate tests were first used on predictive variables $\left(\mathrm{chi}^{2}\right.$ or exact Fisher test for categorical variables, Student's $t$ test or non-parametric Mann-Whitney or Kruskal-Wallis tests for continuous variables), and were then followed by a step-by-step multivariate logistic regression analysis to determine the odds ratios (OR) and their $95 \%$ confidence intervals $(95 \% \mathrm{Cl})$ and $p$ values. The BIPQ scores and sub-scores were described taking into account the ARIA classification (mild and intermittent/mild and persistent/moderate to severe and intermittent/moderate to severe and persistent), and the degree of disease control (ARCT score $\geq 20 /<20$ ). The Pearson correlation coefficient was calculated between the BIPQ and ARCT scores. There was no replacement of missing data for the explicative variable (BIPQ score). Sample size was calculated for $80 \%$ power and an alpha risk of $5 \%$ to allow identification of factors associated with a BIPQ class with an $O R \geq 1.5$, assuming disease perception would be poor (BIPQ $\geq 5)$ in $50 \%$ of subjects and the smallest class of associated factors at $9 \%$. On this basis, according to the formula of Casagrande et al. ${ }^{21}, 2362$ analysable cases were required for the study. Considering a $5 \%$ rate of unanalysable data, it was planned to include 2486 patients in the survey.

\section{Reporting summary}

Further information on research design is available in the Nature Research Reporting Summary linked to this article

\section{DATA AVAILABILITY}

The data that support the findings of this study are available from the corresponding author upon reasonable request.

Received: 20 May 2020; Accepted: 3 July 2020; Published online: 20 August 2020

\section{REFERENCES}

1. World Health Organization. Integrated chronic disease prevention and control https://www.who.int/chp/about/integrated_cd/en/ (2020).

2. Broadbent, E., Petrie, K. J., Main, J. \& Weinman, J. The brief illness perception questionnaire. J. Psychosom. Res. 60, 631-637 (2006).

3. Demoly, P. et al. Prevalence of asthma control among adults in France, Germany, Italy, Spain and the UK. Eur. Respir. Rev. 18, 105-112 (2009).

4. Price, D., Fletcher, M. \& van der Molen, T. Asthma control and management in 8,000 European patients: the REcognise Asthma and LInk to Symptoms and Experience (REALISE) survey. NPJ Prim. Care Resp. Med. 24, 14009 (2014).

5. ISAAC. International Study of Asthma and Allergies in Childhood (ISAAC), http:// isaac.auckland.ac.nz/resources/resources.php?menu=res (2020).

6. Klossek, J. M., Annesi-Maesano, I., Pribil, C. \& Didier, A. [INSTANT: national survey of allergic rhinitis in a French adult population based-sample]. Presse Med. 38 1220-1229 (2009).

7. Demoly, P. et al. Assessment of disease control in allergic rhinitis. Clin. Transl. Allergy 3, 7 (2013).
8. Bousquet, J. et al. Allergic rhinitis and its impact on asthma (ARIA) 2008 update (in collaboration with the World Health Organization, GA(2)LEN and AllerGen). Allergy 63(Suppl 86), 8-160 (2008).

9. Didier, A. [Characteristics and assessment of allergic rhinitis symptoms: results of the CESAR survey]. Rev. Fr. Allergol. 49, S65-S68 (2009).

10. Williams, A. \& Scadding, G. Is reliance on self-medication and pharmacy care adequate for rhinitis patients? Int. J. Clin. Pr. 63, 98-104 (2009).

11. Truong van ut, $C$. et al. [Knowledge and behavior of patients with allergic rhinitis during a consultation with primary care in general practitioner]. Rev. Fr. Allergol. 52, 429-436 (2012).

12. Demoly, P. et al. [The offer of care in Allergology in 2011]. Rev. Fr. Allergol. 51, 64-72 (2011).

13. Cardell, L. O. et al. TOTALL: high cost of allergic rhinitis-a national Swedish population-based questionnaire study. NPJ Prim. Care Resp. Med. 26, 15082 (2016).

14. Demoly, P., Jankowski, R., Chassany, O., Bessah, Y. \& Allaert, F. A. Validation of a self-questionnaire for assessing the control of allergic rhinitis. Clin. Exp. Allergy $\mathbf{4 1}$, 860-868 (2011).

15. Broadbent, E. et al. A systematic review and meta-analysis of the Brief Illness Perception Questionnaire. Psychol. Health 30, 1361-1385 (2015).

16. Demoly, P., Bosse, I., Fontaine, J. F., Bonniaud, P. \& Just, J. [Allergology: the contribution of care pathways]. Rev. Fr. Allergol. 58, 373-382 (2018).

17. Demoly, P. et al. Development of algorithms for the diagnosis and management of acute allergy in primary practice. World Allergy Organ. J. 12, 100022 (2019).

18. Migueres, M. et al. Characteristics of patients with respiratory allergy in France and factors influencing immunotherapy prescription: a prospective observational study (Realis). Int. J. Immunopathol. Pharmacol. 24, 387-400 (2011).

19. Brozek, J. L. et al. Allergic rhinitis and its impact on asthma (ARIA) guidelines: 2010 revision. J. Allergy Clin. Immunol. 126, 466-476 (2010).

20. Taytard, A. Rhinite allergique http://www.respir.com/doc/abonne/base/ RhiniteAllergique.asp (2005).

21. Casagrande, J. T., Pike, M. C. \& Smith, C. An improved approximate formula for calculating sample sizes for comparing two binomial distributions. Biometrics 34 483-486 (1978).

\section{ACKNOWLEDGEMENTS}

This study was sponsored and funded by Menarini France (Rungis, France). The sponsor supervised the design and conduct of the study. Isabelle Elias Billon (project manager) contributed significantly as the sponsor's employee. The contract research organisation Euraxi Pharma (Joué-les-Tours, France) was appointed by the sponsor to coordinate the study. The authors would especially like to thank Delphine Etienne (statistics) and Odile Capronnier (medical writing) for their contribution to the PETRA study.

\section{AUTHOR CONTRIBUTIONS}

All authors contributed to the design of the project and to data analysis. P.M. contributed to managing the project. All the authors revised the work critically for important intellectual content and approved the final manuscript. They all ensured that questions related to the accuracy or integrity of any part of the work were appropriately investigated and resolved.

\section{COMPETING INTERESTS}

P.D. has received consulting fees, honoraria for lectures and/or research funding from ALK, ASIT Biotech, AstraZeneca, Bausch \& Lomb, Chiesi, IQVIA, Menarini, Mylan, Novartis, Sanofi, Stallergenes Greer and ThermoFisher Scientific. I.B. reports no competing interest in the context of this study. P.M. is an employee of the sponsor.

\section{ADDITIONAL INFORMATION}

Supplementary information is available for this paper at https://doi.org/10.1038/ s41533-020-00195-8.

Correspondence and requests for materials should be addressed to P.D.

Reprints and permission information is available at http://www.nature.com/ reprints

Publisher's note Springer Nature remains neutral with regard to jurisdictional claims in published maps and institutional affiliations. 
Open Access This article is licensed under a Creative Commons Attribution 4.0 International License, which permits use, sharing, adaptation, distribution and reproduction in any medium or format, as long as you give appropriate credit to the original author(s) and the source, provide a link to the Creative Commons license, and indicate if changes were made. The images or other third party material in this article are included in the article's Creative Commons license, unless indicated otherwise in a credit line to the material. If material is not included in the article's Creative Commons license and your intended use is not permitted by statutory regulation or exceeds the permitted use, you will need to obtain permission directly from the copyright holder. To view a copy of this license, visit http://creativecommons. org/licenses/by/4.0/.

(c) The Author(s) 2020 